\title{
Prevalence and compensation of academic leaders, professors, and trustees on publicly traded US healthcare company boards of directors: cross sectional study
}

\author{
Timothy S Anderson, ${ }^{1}$ Chester B Good, ${ }^{2}$ Walid F Gellad ${ }^{3}$
}

${ }^{1}$ Department of Internal Medicine, University of

Pittsburgh Medical Center, Pittsburgh, PA, USA

${ }^{2}$ Center for Health Equity Research and Promotion, VA Pittsburgh Healthcare System; VA Center for Medication Safety, Department of Veterans Affairs; University of Pittsburgh School of Medicine, Pittsburgh, PA, USA 3University of Pittsburgh Center for Pharmaceutical Policy and Prescribing and Division of General Internal Medicine; Center for Health Equity Research and Promotion, VA Pittsburgh Healthcare System, Pittsburgh, PA, USA

Correspondence to: W F Gellad, VA Pittsburgh Healthcare System, Pittsburgh, PA 15240,USAwfg3@pitt.edu

Additional material is published online only. To view please visit the journal online (http://dx.doi. org/10.1136/bmj.h4826)

Cite this as: $B M J$ 2015;351:h4826 doi: 10.1136/bmj.h4826

Accepted: 27 August 2015

\begin{abstract}
OBJECTIVE

To identify the prevalence, characteristics, and compensation of members of the boards of directors of healthcare industry companies who hold academic appointments as leaders, professors, or trustees.

DESIGN

Cross sectional study.

SETTING

US healthcare companies publicly traded on the NASDAQ or New York Stock Exchange in 2013.

\section{PARTICIPANTS}

3434 directors of pharmaceutical, biotechnology, medical equipment and supply, and healthcare provider companies.
\end{abstract}

\section{MAIN OUTCOME MEASURES}

Prevalence, annual compensation, and beneficial stock ownership of directors with affiliations as leaders, professors, or trustees of academic medical and research institutions.

\section{RESULTS}

446 healthcare companies met the study search criteria, of which 442 (99\%) had publicly accessible disclosures on boards of directors. 180 companies (41\%) had one or more academically affiliated directors. Directors were affiliated with 85 geographically diverse non-profit academic institutions, including 19 of the top 20 National Institute of Health funded medical schools and all of the 17 US News honor roll hospitals. Overall, these

\section{WHAT IS ALREADY KNOWN ON THIS TOPIC}

Academic leaders frequently serve on pharmaceutical industry boards of directors and receive substantial cash compensation that results in conflicts of interest between their academic and industry roles

Until now the prevalence of these relationships among other members of academia and other sectors of healthcare has been lacking

\section{WHAT THIS STUDY ADDS}

Nearly 1 in 10 US for profit healthcare company directorships are held by academically affiliated individuals, including academic leaders, professors, and trustees from 85 major non-profit academic institutions

$41 \%$ of publicly traded US healthcare companies included at least one academically affiliated director, and these directors received substantial cash fees and stock shares for serving as directors

Dual obligations to for profit companies and non-profit academic institutions create diverse individual and institutional conflicts that vary in gravity and reconcilability depending on an individual's academic roles; these conflicts have not been fully addressed by previous guidelines and warrant additional review, regulation, and, in some cases, prohibition when conflicts cannot be reconciled
279 academically affiliated directors included 73 leaders, 121 professors, and 85 trustees. Leaders included 17 chief executive officers and 11 vice presidents or executive officers of health systems and hospitals; 15 university presidents, provosts, and chancellors; and eight medical school deans or presidents. The total annual compensation to academically affiliated directors for their services to companies was $\$ 54995786$ (£35836000; $€ 49185900$ ) (median individual compensation \$193000) and directors beneficially owned 59831477 shares of company stock (median 50699 shares).

\section{CONCLUSIONS}

A substantial number and diversity of academic leaders, professors, and trustees hold directorships at US healthcare companies, with compensation often approaching or surpassing common academic clinical salaries. Dual obligations to for profit company shareholders and non-profit clinical and educational institutions pose considerable personal, financial, and institutional conflicts of interest beyond that of simple consulting relationships. These conflicts have not been fully addressed by professional societies or academic institutions and deserve additional review, regulation, and, in some cases, prohibition when conflicts cannot be reconciled.

\section{Introduction}

As the for profit healthcare industry and academic medicine have grown closely intertwined, financial relationships between industry and academia and the risks of conflicts of interest have come under scrutiny. ${ }^{1}$ Physicians $^{2-4}$ and the media ${ }^{56}$ have highlighted concerns that secondary financial interests of individuals and companies may create an undue influence on primary patient care, research, and education goals. Professional societies ${ }^{278}$ and government bodies ${ }^{9}$ have focused attention on illuminating financial ties between industry and physicians in an effort to differentiate collaborative partnerships that create benefits for patients and society from those that bias judgment in clinical and administrative decision making. In the United States and United Kingdom, professional guidelines have called for disclosing and occasionally limiting certain types of financial relationships between physicians, researchers, and industry. ${ }^{278}$

The attention of professional guidelines and the media has primarily focused on researchers and clinicians who receive financial payments for conducting industry research, providing consulting services, and giving promotional lectures. Less attention is paid to academic individuals who also serve on the boards of 
directors of for profit healthcare companies. Boards of directors are elected by shareholders annually, with responsibilities including oversight of executive officers, setting major strategic initiatives, and handling major financial decisions such as mergers. ${ }^{10}$ Similar to individuals engaging in consulting relationships, directors on industry boards enter a formal contract with the company and receive financial payment for services; however, they are subject to two important differences. Firstly, unlike consultants who are compensated to provide expertise on a specific issue, directors are subject to a fiduciary responsibility to company shareholders to advance the general interests of the company and increase profits. Secondly, directors are reimbursed both through larger cash fees than typical consulting contracts and through stock options, the value of which is directly tied to the financial success of the company. Serving as a director has largely been unaddressed in professional society guidelines. Even the US Physician Payments Sunshine Act, which requires nearly all payments to physicians and academic medical centers to be reported annually by pharmaceutical and medical device companies, does not explicitly require separate reporting of payments for serving as a company director. ${ }^{11}$

We previously documented that the 47 largest global pharmaceutical companies often have academic medical center leaders on their boards, and that annual cash payments to individual directors average over $\$ 300000 .^{12}$ However, conflicts are not specific to medical leadership, as any physician, medical researcher, or medical leader who enters into a company directorship develops a conflict of interest between their primary professional obligations to their academic institution and their fiduciary responsibility to company shareholders and personal financial gain linked to stock ownership. Additionally, these conflicts of interest are not specific to pharmaceutical companies, as competing interests may impact healthcare service and medical equipment industries as well. Though the missions of academia and for profit companies can overlap, they may also diverge, specifically when the for profit mission of industry competes with the non-profit taxpayer funded clinical and research missions of academic medical and research institutions.

In an effort to understand better the scope of this particular relationship between academia and industry, we examined the presence of leaders, professors, and trustees of academic medical and research institutions who serve on company boards of directors within the entire US healthcare sector by using public disclosures from companies to the US Securities and Exchange Commission.

\section{Methods}

\section{Data sources}

We used the Industry Classification Benchmark, a taxonomy used by stock exchanges, to identify all publicly traded healthcare companies listed on the NASDAQ exchange and New York Stock Exchange, the two largest global stock exchanges, in January 2014. ${ }^{1314}$
The Industry Classification Benchmark divides healthcare companies into 14 subsectors, which we grouped into four broad categories: pharmaceuticals (major pharmaceuticals and other pharmaceuticals), biotechnology (biological products, commercial physical and biological research, electromedical and electrotherapeutic apparatus, and in vitro and in vivo diagnostic substances), medical equipment and supplies (industrial specialties, medical electronics, medical or dental instruments, ophthalmic goods, and precision instruments), and healthcare providers (hospital or nursing management, medical specialties, medical or nursing services).

\section{Study design}

We examined the characteristics and formal relationships of members of healthcare companies' boards of directors for 2013. We limited our study to US companies, given the availability of public data on board composition, biographies of directors, and compensation. Data were collected in January 2014 from 2013 definitive proxy statements, DEF 14A forms, for each company. Definitive proxy statements are required to be submitted annually before shareholder meetings and are publicly available through the Securities and Exchange Commission's electronic data gathering, analysis, and retrieval system. ${ }^{15}$ For each company we identified the number of directors, number with one or more academic affiliations, and number with graduate level clinical training (medicine, nursing, pharmacy, or dentistry).

Individuals who were directors at multiple companies were counted separately for each directorship for prevalence and compensation analyses but combined for summary statistics on academic affiliations. We counted individuals who held both leadership and professorial or trustee positions at academic institutions only as leaders. Individuals who held multiple leadership roles at distinct institutions (for example, an individual who was both the dean of a medical school and the chief executive officer of a hospital) were counted as holding two academic positions.

Definition and classification of academic affiliations We defined an academic medical or research institution affiliation as a formal position at a US medical school, affiliated teaching hospital, or health system; overseeing research university; or medical research institute with a medical school partnership. ${ }^{16}$ We classified individuals with academic affiliations as leaders, professors, or trustees, as each group holds a different set of responsibilities to their academic institutions that poses unique conflicts with their obligations as for profit company directors.

Leaders were defined as individuals holding positions that involve oversight of the clinical activities of their institution (hospital and health system executive officers and clinical department chairs) or educational and research activities (university presidents, provosts, chancellors, deans, and department chairs of health science schools, including medicine, pharmacy, nursing, and public health, and directors of interdisciplinary 
translational research institutes akin to departments). Leaders who hold company directorships are subject to both individual and institutional conflicts of interest. The institutional conflicts of interest arise when secondary interests influence or risk influencing institutional processes such as the selection of staff for hiring or promotion, decisions on purchasing and formulary, setting institutional research agendas, and setting educational goals. ${ }^{117}$

Professors were defined as individuals holding an assistant, associate, or full professorship. Professors were subdivided into clinical professors and preclinical research professors based on their department. We included only professors with appointments within health science schools, including medicine, pharmacy, nursing, and public health, or within science and engineering departments with individual research focuses directly related to commercial products (for example, chemistry professor studying pharmaceuticals, or biomedical engineering professor studying artificial joints). We excluded adjunct positions. Clinical professors face individual conflicts of interest when their primary duties as clinicians, educators, or researchers risk undue influence from the profit oriented goals of their companies. Research professors who may be developing new therapeutics (that is, biochemistry professors), new medical devices (that is, biomedical engineering professors), or new models of healthcare (that is, health policy and public health professors) face similar conflicts between their primary duties to their trainees, research funders (including the US government), and the for profit missions of healthcare companies. ${ }^{1}$

Academic trustees were defined as individuals who held trustee positions on hospital, medical school, or overseeing university boards of trustees. We excluded research and fundraising advisory positions as these roles are often voluntary without a contractual relationship between the institution and individual. Trustees who hold company directorships face institutional conflicts of interest as they are contractually obligated to advise and advance the institutional missions of both the non-profit academic institution and the for profit company. ${ }^{10}$ Similar to company directors, academic trustees oversee the development of institutional strategic initiatives, recruitment of leadership, and approval of financial partnerships and mergers.

\section{Compensation}

For each academically affiliated individual who served as a director for the entire fiscal year, we collected the total compensation for board membership and beneficial stock ownership in the affiliated company. Total compensation figures, as defined by the Securities and Exchange Commission, reflect total annual compensation for services on boards of directors, including cash, stock awards, option awards, dividends, and charitable contribution matching. For compensation analysis, we excluded company executive officers, as their compensation reflects services beyond board membership. Beneficial stock ownership includes shares currently held and shares of common stock issuable pursuant to exercises of stock options within 60 days of the DEF 14A form submission, but excludes restricted stock units and phantom stock. Beneficial stock may include awards reported as part of total compensation as well as stock purchases and awards from previous years. ${ }^{15}$

\section{Results}

Of the 479 unique healthcare companies listed in January 2014 on the NASDAQ or New York Stock Exchange, 21 were newly formed and 12 had merged in 2013 and thus did not have available DEF 14A forms. Of the remaining 446 companies, 442 (99\%) had accessible 2013 DEF 14A forms and were included in the study. Overall, 166 were pharmaceutical companies, 107 biotechnology companies, 94 medical equipment and supply companies, and 75 healthcare provider companies (see supplementary table 1).

\section{Proportion of healthcare companies with academically affiliated directors}

In total, 180 out of 442 companies (41\%) included at least one academically affiliated director. There were 279 directors affiliated with academic institutions, holding 309 out of a total of 3434 (9.0\%) healthcare directorships. Seventy three academic leaders held 85 healthcare company directorships, 121 professors held 132 directorships, and 85 trustees held 93 directorships. Seven leaders and four professors held secondary positions as academic trustees.

\section{Characteristics and academic positions of academically affiliated directors}

Table 1 shows the division of directorships by sector, as well as relevant characteristics of directors. The majority of academically affiliated directorships were held by individuals with clinical training (167/309, 54\%), predominately in internal medicine or related subspecialties. The most common specialties were general internal medicine, cardiology, and oncology. In each sector, most of the academically affiliated directors with clinical training held positions in clinical departments, with the exception of healthcare provider companies in which nearly half of directorships were held by individuals with executive administration roles. Table 2 provides a sample of actual academic titles of leaders, professors, and trustees on company boards as well as the qualifications they brought to the company as reported on company proxy statements.

Table 3 lists the academic roles held by company directors. Of the 73 leaders who served as directors, seven held duals roles as chief executive officer of a health system, and dean, chancellor, or vice president of a partner medical school or university. There were four hospital chief executive officers, 13 health system chief executive officers, and 11 vice presidents or executive officers of hospitals and health systems. There were nine presidents and six provosts or chancellors of research universities, and three university and research institute vice presidents or executive officers. Leaders also included eight presidents or deans of medical schools, and three deans of other health science 


\begin{tabular}{|c|c|c|c|c|c|}
\hline Characteristics & $\begin{array}{l}\text { All healthcare } \\
\text { companies } \\
(n=442)\end{array}$ & $\begin{array}{l}\text { Pharmaceutical } \\
(n=166)\end{array}$ & $\begin{array}{l}\text { Biotechnology } \\
(n=107)\end{array}$ & $\begin{array}{l}\text { Medical equipment } \\
\text { and supply }(n=94)\end{array}$ & $\begin{array}{l}\text { Healthcare } \\
\text { provider } \\
(\mathrm{n}=75)\end{array}$ \\
\hline Directorships (No) & 3434 & 1290 & 762 & 746 & 636 \\
\hline $\begin{array}{l}\text { Directorships held by individuals with } \\
\text { academic affiliation* }(\%)\end{array}$ & $309(9.1)$ & $129(10.0)$ & $63(8.3)$ & $60(8.0)$ & $57(9.0)$ \\
\hline $\begin{array}{l}\text { Directorships held by individuals with } \\
\text { clinical training and academic affiliation (\%): }\end{array}$ & $167(4.9)$ & $66(5.1)$ & $34(4.5)$ & $32(4.3)$ & $35(5.5)$ \\
\hline Medical specialty & $79(47.3)$ & 43 & 17 & 10 & 9 \\
\hline Surgical specialty & $29(17.4)$ & 10 & 3 & 9 & 7 \\
\hline General medicine & $21(12.6)$ & 6 & 3 & 4 & 8 \\
\hline Pathology or radiology & $11(6.6)$ & 2 & 5 & 3 & 1 \\
\hline Pediatrics & $8(4.8)$ & 1 & 2 & 1 & 4 \\
\hline Obstetrics and gynecology & $7(4.2)$ & 2 & 1 & 3 & 1 \\
\hline Psychiatry & $3(1.8)$ & 0 & 1 & 0 & 2 \\
\hline Other graduate clinical training & $8(4.8)$ & 1 & 2 & 2 & 3 \\
\hline Graduate medical training not available & $1(0.6)$ & 1 & 0 & 0 & 0 \\
\hline \multicolumn{6}{|l|}{ Current academic appointmentt: } \\
\hline Clinical department & $88(52.3)$ & 37 & 21 & 19 & 11 \\
\hline Executive administration & $45(27.0)$ & 14 & 6 & 9 & 16 \\
\hline Preclinical department & $25(15.0)$ & 11 & 6 & 4 & 4 \\
\hline Academic trustee & $9(5.4)$ & 4 & 1 & 0 & 4 \\
\hline
\end{tabular}

*Individuals who held directorships at multiple companies were counted separately for each directorship.

tFor the 167 clinically trained directors at the time of definitive proxy statement disclosure.

\section{Table 2 | Academic director benefits to companies and resulting potential conflicts of interest}

Academic roles*

Researchers:

Professor of neurology Qualifications for company directorship*

\section{Potential conflicts of interest}

Company goal of developing products to generate revenue versus academic research goal of understanding human physiology and developing effective treatments for disease states regardless of profit

Professor of medicine, Experience in the practice of medicine and clinical trials provides the board and member of hospital conflict management with the perspectives of physicians who use the company's

of interest committee products and with insight into the clinical trial process. Service on the academic

Potential for bias in decisions of director in their role on the conflict of interest committee regarding clinical trials or research related to the company or their competitors institution's conflict of interest committee provides the company with important insights on the ethics of healthcare

\section{Clinicians: \\ Professor of orthopedic surgery}

\section{hospital managerial experience.}

Experience as a nationally known professor of obstetrics and gynecology as well as the director's experience with performing scientific research and developing and implementing educational programs for physicians

Professor of obstetrics and gynecology

\section{Professor of medicine and} member of two medical journal editorial boards

Administrative leaders:

Chair, department of medicine

\section{Recognized healthcare thought leader. This expertise is vital in shaping our} strategy to deliver innovative and expanded service offerings

Experience as a practicing physician, a scientist and a nationally recognized leader in academic medicine. Oversees a large research portfolio and an extensive research and education budget at the academic institution, giving the director a valuable perspective on drug discovery and development

Chief executive officer, academic health system

Extensive business, managerial, executive, and leadership experience in the healthcare industry, having served in numerous senior management positions, including as chief executive officer at a leading hospital and healthcare system

Vice chancellor for research and chairman of pharmacy and therapeutics committee

Trustees:

Health system trustee and chair of the investment committee

Medical school trustee
The director's medical background is extremely valuable as the company seeks to continue expanding its pipeline with promising products that offer advancement to patient care and are well positioned competitively

Experience in serving as a director of several companies, financial expertise, and service with other healthcare organizations

The director's position as our chief executive officer and the director's significant experience in the cancer research field and corporate strategy development, including executive leadership roles at global pharmaceutical companies, and experiences in commercializing potential drug candidates
Academic goal of providing trainees with evidencebased, unbiased surgical training vs. company goal of increasing training of their specific products.

Academic goal to provide cost-effective care vs. company goal of promoting company products

Company goal of developing research results that support product sales versus journal editor role to promote evidence based, unbiased, research results

Potential for director responsibility to increase company profits to bias decisions when setting departmenta research and educational goals

Potential for director's fiduciary responsibility to shareholders and personal financial gain to bias decisions related to hiring and promotion of faculty as well as developing new clinical centers or services Potential for bias in decision on hospital formulary decisions related to company and competitor products. Potential for bias in setting research agenda of the academic institution

Fiduciary responsibility to company to increase profit may conflict with responsibility to hospital to manage investments

Role as both director and chief executive officer of company may bias strategic decisions at medical school related to investments and educational priorities

\footnotetext{
*As noted in definitive proxy statements. Academic roles and qualifications paraphrased from company definitive proxy statements for anonymity of individual, academic institution, and company.
} 
schools. Sixteen individuals held positions as department chairs, eight in clinical departments and eight in preclinical research departments; additionally, four individuals directed interdisciplinary translational research institutes. Of the 121 professors who served as directors, 14 held professorships in both a clinical and a preclinical research department, 76 held a clinical professorship, and 31 held professorships in preclinical research departments.

Additionally, 85 company directors served as academic trustees, often of multiple institutions. The 85 individuals held 93 academic trustee positions: 57 served as trustees of hospitals or health systems, of whom 13 also served as a university trustee, 22 as trustees of overseeing universities, and six as trustees of medical schools, of whom three served as trustees of both a medical school and an overseeing university.

\section{Company compensation to academically affiliated directors}

Of the 309 directorships held by individuals with academic affiliations, 26 individuals who held executive positions at companies and seven directors appointed midway through the year were excluded in compensation analysis. Total compensation to individuals affiliated with academic institutions for holding the remaining directorships was \$54995786 (£35836000; $€ 49185900)$. Individual compensation ranged from $\$ 0$ to $\$ 1.43 \mathrm{~m}$, with a median of $\$ 193000$ (interquartile range \$102000-\$271000) (table 3). Beyond annual compensation, board members beneficially owned major company stock, totaling 59831477 shares (median 50699, interquartile range 25925-140994). Table 3 provides additional details on compensation to academic leaders, professors, and trustees.

\section{Academic medical and research institutions represented by company directors}

Directors were affiliated with a total of 85 academic institutions in 27 US states, including 63 institutions with both a medical school and an overseeing university, six freestanding medical schools, nine research universities conducting biomedical research, four freestanding teaching hospitals with graduate medical education programs, and three non-profit medical research institutes (table 4). All academic institutions were nonprofit and 38 (44.7\%) were publicly owned. Nineteen of the top 20 medical schools in terms of National Institutes of Health $(\mathrm{NIH})$ research funding had at least one leader or professor who served as a healthcare company director, whereas none of the 20 lowest NIH funded medical schools had individuals on company boards. ${ }^{18}$ In terms of clinical reputation, all 17 US News and World Report 2013 honor roll hospitals had individuals on company board of directors. ${ }^{19}$ Table 4 also reports financial compensation to directors by academic institution affiliation.

\section{Discussion}

Overall, 85 non-profit academic institutions, including many of the most renowned medical research and clinical centers had at least one leader, professor, or trustee

Table 3 | Compensation and beneficial stock ownership to academic leaders, professors, and trustees for serving as directors of publicly traded healthcare companies

\begin{tabular}{|c|c|c|c|c|}
\hline Academically affiliated directors & $\begin{array}{l}\text { No of } \\
\text { individuals }\end{array}$ & $\begin{array}{l}\text { Total No of company } \\
\text { directorships } \\
\text { held }\end{array}$ & $\begin{array}{l}\text { Median (interquartile range) } \\
\text { annual compensation per } \\
\text { directorship^(\$) }\end{array}$ & $\begin{array}{l}\text { Total No of } \\
\text { beneficially owned } \\
\text { stock shares* }\end{array}$ \\
\hline Leaders, professors, and trustees & 279 & 309 & $193000(102000-271000)$ & 59831477 \\
\hline Leaderst: & $73+$ & $85+$ & $209000(103000-271000)$ & 5493946 \\
\hline $\begin{array}{l}\text { Hospital and health system chief executive } \\
\text { officers }\end{array}$ & 17 & 21 & $221000(152000-277000)$ & 891351 \\
\hline $\begin{array}{l}\text { Hospital and health system vice presidents } \\
\text { and executive officers }\end{array}$ & 11 & 13 & 147000 (81 000-192000) & 641912 \\
\hline $\begin{array}{l}\text { University and research institute presidents, } \\
\text { provosts, and chancellors }\end{array}$ & 15 & 17 & $185000(104000-199000)$ & 1801756 \\
\hline $\begin{array}{l}\text { University and research institute vice } \\
\text { presidents and executive officers }\end{array}$ & 3 & 5 & $193000(189000-194000)$ & 192909 \\
\hline Health science school deans and presidents & 11 & 17 & $268000(105000-305000)$ & 545917 \\
\hline Department chairs & 16 & 18 & $103000(67000-222000)$ & 1180334 \\
\hline Interdisciplinary institute directors & 4 & 4 & $173000(97000-245000)$ & 599296 \\
\hline Professors: & 121 & 131 & $160000(82000-259000)$ & 22513088 \\
\hline Clinical department & 76 & 84 & $158000(81000-253000)$ & 15247749 \\
\hline Preclinical research department & 31 & 32 & $192000(101000-261000$ & 5255549 \\
\hline $\begin{array}{l}\text { Joint appointment clinical and preclinical } \\
\text { departments }\end{array}$ & 14 & 15 & $124000(69000-227000)$ & 2009790 \\
\hline Academic trustees: & 85 & 93 & $227000(145000-278000)$ & 31824443 \\
\hline Hospital or health system & 44 & 46 & $229000(124000-279000)$ & 12218861 \\
\hline Research university & 22 & 23 & $251000(140000-278000)$ & 16349837 \\
\hline Medical school & 3 & 3 & $211000(156000-265000)$ & 254877 \\
\hline Multiple trustee positions & 16 & 21 & $212000(170000-257000)$ & 3000868 \\
\hline \multicolumn{5}{|c|}{$\begin{array}{l}\$ 1.00 \text { ( } £ 0.65 ; € 0.89) \text {. } \\
\text { *Compensation excluded the two leaders, eight professors and } 15 \text { academic trustees who held positions as company executive officers positions in } \\
\text { addition to directorships, as well as seven individuals appointed midway through the year. Compensation is rounded to the nearest thousand dollars. } \\
\text { tSeven health system chief executive officers held concurrent positions as deans or executive officers of affiliated academic institutions and are listed } \\
\text { twice within leader subcategories but counted only once in the total leader compensation. }\end{array}$} \\
\hline
\end{tabular}




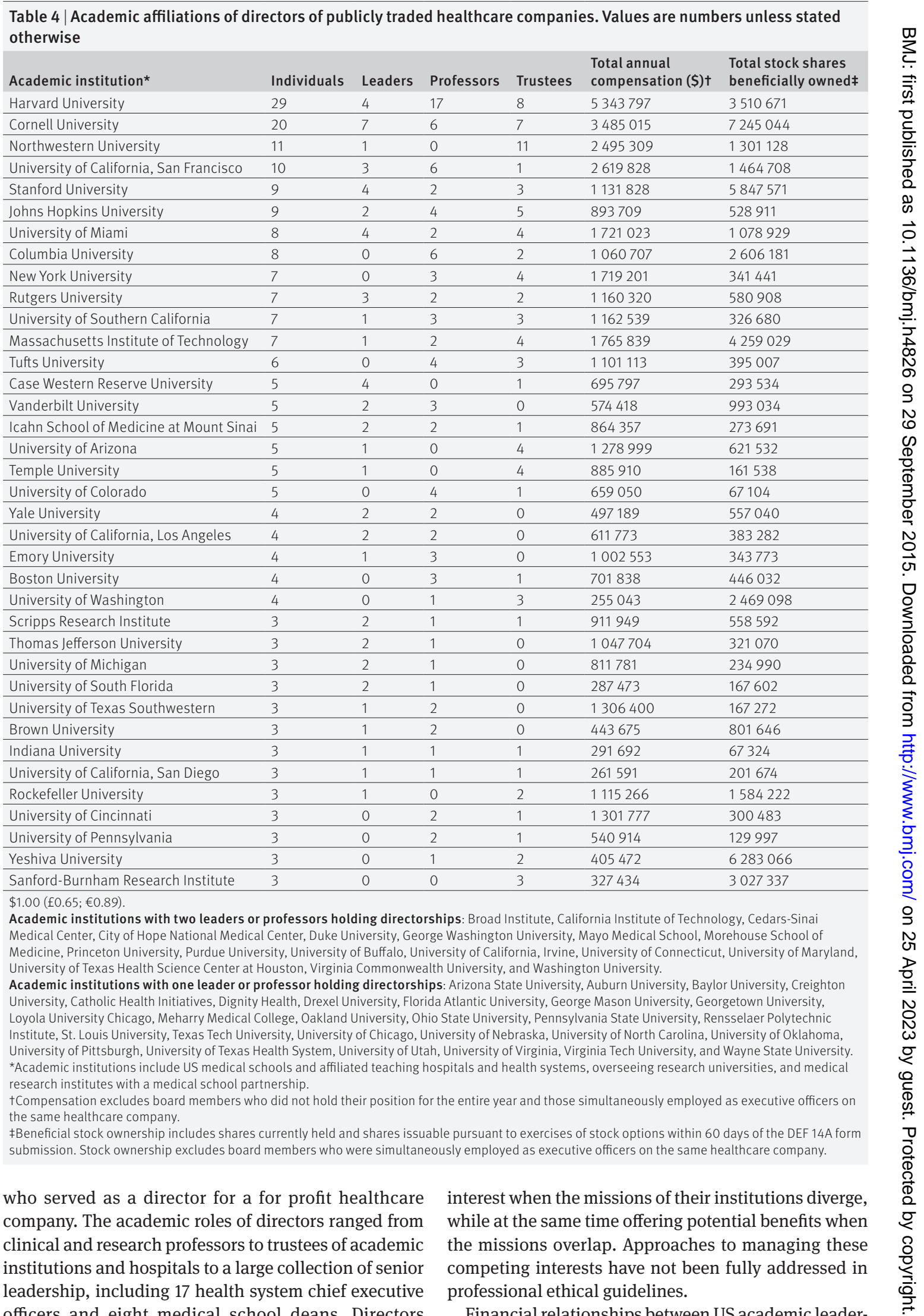

officers and eight medical school deans. Directors received considerable cash compensation and owned a median of 50000 stock shares tied to company performance. The dual obligations to industry and academia that these individuals hold create important conflicts of

Financial relationships between US academic leadership and the pharmaceutical industry have been well documented..$^{12172021}$ A 2006 survey of department chairs found $60 \%$ of respondents had a relationship to industry, with $11 \%$ serving on a company board of directors. ${ }^{17}$ 
A 2009 study of medical school deans documented nine deans who served on company boards of directors, with a median compensation of over $\$ 200000 .{ }^{21}$ We previously documented US academic leadership that held directorships at 19 of the 47 largest global pharmaceutical companies. ${ }^{12}$ This study extends the scope of our understanding of these dual roles in three key ways: by using company reported data to examine $99 \%$ of publicly traded US healthcare companies across all sectors, examining a wider spectrum of academically affiliated individuals beyond leaders, and providing a more detailed examination of the magnitude of financial relationships, including stock ownership.

\section{Risks and benefits}

What are the risks and benefits of academic leaders, professors, and trustees serving on for profit company boards? There is no doubt that collaboration between academic institutions and industry has led to profoundly important clinical trials, drug development, and translational research initiatives, although the role and necessity of academically affiliated directors in facilitating these projects is unclear and undocumented. There are potential benefits to having greater representation of the non-profit healthcare sector in the corporate board room, and academic institutions may directly benefit from their leaders, professors, and trustees developing management skills and forging fundraising or research partnerships. ${ }^{10}$ However, these same director qualifications and connections can be the source of conflicting interests when individuals have a primary obligation as a clinician, researcher, administrator, educator, or institutional leader in academia while holding a secondary fiduciary responsibility to promote company shareholder interests. Table 2 provides examples of these potential conflicting interests.

One difficulty in developing guidelines to manage these competing interests is that their potential harms vary depending on the individual's primary academic duties. For instance, a molecular genetics professor who serves on a biotechnology company board holds a primary academic mission of conducting innovative basic science research in the public's best interest and providing unbiased mentorship to trainees; at the same time, the professor is obligated to the company mission of developing marketable products. This set of conflicts is different from that of the 73 institutional leaders and 85 trustees identified in this study, who hold academic responsibilities in selecting faculty for hiring and promotion, planning capital, structural and staff investments, and shaping institutional research priorities. These responsibilities may be influenced by their fiduciary obligation to a company that seeks to invest in profitable clinical initiatives and bring products to market. ${ }^{17}$

Understanding the diversity of these conflicts is vital, given that some may be amenable to appropriate oversight and management and some may be irreconcilable. Previous recommendations for managing financial relationships with industry have focused primarily on pharmaceutical and medical device companies, but these make up only $59 \%$ of publicly traded US healthcare companies. Relationships between academia and healthcare provider companies, such as pharmaceutical benefit managers and health insurers, may create different conflicts. For example, when a hospital chief executive officer or trustee has a relationship with a health insurer, that relationship could influence, or perceive to influence, negotiations with insurers on reimbursement. Furthermore, previous guidelines have emphasized the relationships of clinicians and researchers with industry, but institutional conflicts of interest, which arise when administrators, including executive officers, trustees, and clinical leaders have a financial relationship with industry, are increasingly recognized and pose a unique set of risks to academic missions. ${ }^{172223}$ Though we identified 121 professors who hold company directorships and thus risk an individual conflict of interest, we found an even greater number of leaders and trustees with directorships with an attendant risk of institutional conflicts of interest. This study, by describing the diversity of directors' academic roles and the variety of sectors of healthcare represented, can assist institutions in crafting more comprehensive guidelines for the management of these conflicts.

\section{Managing conflicts of interests created by company} directorships

Two recent perspective pieces provide deeper context on the risks and difficulty of holding obligations to two separate institutions. Pisano, Golden, and Schweitzer write that "having a fiduciary responsibility to two separate entities is at best a very difficult situation," citing concerns of directing academic business to companies inappropriately and using inside information about the academic institution to guide company strategy. ${ }^{22}$ The authors, themselves senior academic leaders and one an uncompensated board member of a healthcare company, go on to suggest that academic leadership should not be permitted to hold paid relationships with outside companies unless there is a compelling institutional interest in having a leader serve in such a role, such as when an individual founds a start-up company within an academic institution and partners with a healthcare company, and if the role with the company is outside the scope of the leader's academic role. In the second piece, Bernard Lo, chairman of a 2009 Institute of Medicine report on conflict of interest, provides a detailed analysis of the likelihood of irreconcilable conflicts that arise when an academically affiliated individual serves on a company board of directors and is therefore "serving two masters." Lo sets goals for policymakers in crafting conflict of interest policies for managing directorships, which include identifying situations of divergence between academic and industry goals, identifying strategies that may ameliorate risks to the academic institution, identifying strategies to preserve beneficial relationships while reducing risks, determining the acceptable magnitude of financial payments for directorships, and developing effective institutional oversight. ${ }^{23}$

Several approaches have been taken to managing financial relationships between industry and academia: public disclosure, institutional review, and regulation. 
Public disclosure is an increasingly common approach that avoids restricting relationships, allowing patients with the time and interest to examine physician's disclosure documents on a website or in the office. The impact of disclosure by leaders and researchers is unclear, though it may allow trainees, employees, and payers to evaluate the financial ties of academic institutions. However, disclosure ameliorates neither the competing interests faced by individuals with dual roles nor the potential for biased outcomes. Secondly, institutional review of financial relationships is recommended by many professional societies. ${ }^{24-26}$ When it leads to oversight and prohibition of certain activities, review may help institutions ensure that individuals who serve as company directors are not involved in decisions that their relationship might bias, such as prohibiting the individual in table 2 who chairs a purchasing and formulary committee from participating in decisions related to his or her company's or a competing company's products. However, guidelines for institutional review are lacking, outcomes have not been described, and previous authors have highlighted the challenges in review pertaining to leadership with financial relationships, most notably the difficulty in ensuring adequate management when employees are asked to review their supervisors. 2223

Regulation of financial conflicts may come by way of case by case review or through overarching institutional policies. What forms of regulation might best address the specific conflicts posed by directorship? The potential for bias posed by the magnitude of financial gain may be partially mitigated by limiting payments to academic directors, a strategy pursued by a handful of academic institutions. ${ }^{2223}$ Our finding that academically affiliated directors hold a median of 50000 company stock shares suggests that individuals have a stronger than previously documented financial incentive, directly tied to the company's financial success, that might be partially ameliorated by restricting payment to fees and prohibiting the receipt of stock options. Another option is to fully prohibit directorships while allowing employees to engage in other industry interactions, such as serving on advisory boards and as expert consultants with appropriate oversight, thus preserving potentially beneficial academic-industry relationships while removing the unique risk of holding a fiduciary responsibility to shareholders. Finally, fully prohibiting relationships is an option; for instance, the UK National Institute for Health and Care Excellence has fully excluded individuals with financial relationships with industry in participating from writing guidelines. ${ }^{9}$

\section{Limitations of this study}

Several limitations of this study deserve mention. Firstly, our methods were intentionally conservative, looking only at active relationships among academic leaders, professors, and trustees. We excluded non-US faculty, emeritus faculty, advisory board members, and individuals with recent academic relationships that ended before the submission of definitive proxy statements. Secondly, we relied on public company disclosures of compensation and beneficially owned stock that cannot be independently verified. As the Securities and Exchange Commission only requires DEF 14a forms for publicly traded US companies, our study population excluded large privately held companies such as Purdue Pharmaceuticals, major foreign companies such as GlaxoSmithKline, and small start-up companies, all of which may have academically affiliated board members. As a result of these two limitations, our study likely underreports the full scope of ties between industry directors and academia. Thirdly, we rely on company disclosure of academic affiliations, and when possible we verified relationships with academic websites; however, not all public information may be fully up to date. Finally, we do not make any conclusions about whether a specific academic-industry relationship we identified led to an actual negative outcome; our goal was to characterize these relationships and identify their extent.

\section{Conclusion}

In this study we identified a substantial presence of academically affiliated individuals on the boards of directors of for profit healthcare companies. Compensation received by academically affiliated directors often approached or surpassed common academic clinical salaries and included stock shares, the value of which was contingent on company performance. A diversity of academic leaders, professors, and trustees from 85 major academic institutions held directorships, and their dual obligations to for profit company shareholders and non-profit clinical and educational institutions pose major individual and institutional conflicts of interest beyond that of consulting relationships. These conflicts have not been fully addressed by professional societies or academic institutions and deserve additional review, regulation, and, in some cases, prohibition when conflicts cannot be reconciled.

Contributors: All authors conceived and designed the study, analysed and interpreted the data, and critically revised the manuscript for important intellectual content. TSA acquired the data, drafted the manuscript, and carried out the statistical analysis. He is the guarantor. WFG obtained funding and supervised the study. CBG and WFG provided administrative, technical, or material support. All authors had full access to all of the data in the study and take responsibility for the integrity of the data and the accuracy of the data analysis. This work represents the opinions of the authors alone and does not necessarily represent the views of the Department of Veterans Affairs or the United States Government.

Funding: WFG was supported by a VA Health Services Research and Development award CDA 09-207. The funder had no role in the design and conduct of the study, collection, management, analysis, and interpretation of data, or preparation of the manuscript.

Competing interests: All authors have completed the ICMJE uniform disclosure form at www.icmje.org/coi disclosure.pdf and declare: WFG has received consulting fees from IMS Health and grant funding from Express Scripts for work unrelated to the current manuscript; no other financial relationships with any organisations that might have an interest in the submitted work in the previous three years; no other relationships or activities that could appear to have influenced the submitted work.

Ethical approval: Not required.

Data sharing: All data on members of industry board of directors are publicly available. 
Transparency: The lead author (TSA) affirms that the manuscript is an honest, accurate, and transparent account of the study being reported; that no important aspects of the study have been omitted; and that any discrepancies from the study as planned (and, if relevant, registered) have been explained.

This is an Open Access article distributed in accordance with the Creative Commons Attribution Non Commercial (CC BY-NC 4.0) license, which permits others to distribute, remix, adapt, build upon this work non-commercially, and license their derivative works on different terms, provided the original work is properly cited and the use is non-commercial. See: http://creativecommons.org/licenses/ by-nc/4.0/.

1 Thompson DF. Understanding financial conflicts of interest. N Engl J Med 1993;326:573-6.

2 Institute of Medicine. Conflict of interest in medical research, education, and practice. National Academies Press; 2009. www.iom. edu/Reports/2009/Conflict-of-Interest-in-Medical-ResearchEducation-and-Practice.aspx

3 Avorn J. Powerful medicines: the benefits, risks and costs of prescription drugs. Random House; 2004.

4 Brennan TA, Rothman DJ, Blank L, et al. Health industry practices that create conflicts of interest: a policy proposal for academic medical centers. JAMA 2006;295:429-33

5 ProPublica. Dollars for docs. 2013. http://projects.propublica.org/ docdollars/.

6 Rodwin MA. Conflicts of interest and the future of medicine: the United States, France, and Japan. 1st ed. Oxford University Press, 2011.

7 Association of American Medical Colleges. Industry funding of medical education: report of an AAMC task force. June 2008. https:// members.aamc.org/eweb/upload/Industry\%20 Funding\%20of\%20 Medical\%20Education.pdf

8 National Institute for Health and Care Excellence. Code of practice for declaring and dealing with conflicts of interest: NICE, 2008.

9 US Department of Health and Human Services. Medicare, Medicaid, Children's Health Insurance Programs; transparency reports and reporting of physician ownership or investment interests; final rule. Fed Regist 2013;27:9458-527.

10 Pusser B, Slaughter S, Thomas SL. Playing the board game: an empirical analysis of university trustee and corporate board interlocks. J Higher Educ 2006;77:747-55.

11 Agrawal S, Brennan N, Budetti P. The Sunshine Act-effects on physicians. N Engl J Med 2013;368:1353-5.
12 Anderson TS, Dave S, Good CB, et al. Academic medical center leadership on pharmaceutical company boards of directors. JAMA 2014:311:1353-5.

13 NASDAQ. Health care companies. www.nasdaq.com/screening/ companies-by-industry.aspx?industry=Health+Care.

14 New York Stock Exchange. NYSE Healthcare Index. 2014. www1.nyse. com/about/listed/nypid components.shtml.

15 US Securities and Exchange Commission. Electronic data gathering, analysis, and retrieval system. 2014. www.sec.gov/edgar.shtml.

16 Wartman, SA. The Academic Health Center: Evolving Organizational Models. Association of Academic Health Centers. 2007. www.aahcdc. org/Portals/0/pdf/AAHC_Evolving_Organizational_Models.pdf.

17 Campbell EG, Weissman JS, Ehringhaus S, et al. Institutional academic-industry relationships. JAMA 2007;298:1779-86.

18 Blue Ridge Institute for Medical Research. Ranking tables of NIH funding to US medical schools in 2013. www.brimr.org/NIH Awards/2013/NIH_Awards_2013.htm.

19 US News and World Report. US News \& World Report Releases 2013-14 Best Hospitals Rankings. 2013. www.usnews.com/info/ blogs/press-room/2013/07/16/us-news--world-report-releases2013-14-best-hospitals-rankings.

20 Kesselheim AS, Robertson CT, Siri, K, et al. Distributions of Industry Payments to Massachusetts Physicians. N Engl / Med 2013:368:2049-52.

21 Freshwater DM, Freshwater MF. Failure by deans of academic medical centers to disclose outside income. Arch Intern Med 2011;171:586-7.

22 Pisano ED, Golden RN, Schweitzer L. Conflict of interest policies for academic health system leaders who work with outside corporations. JAMA 2014;311:1111-2.

23 Lo B. Serving two masters-conflicts of interest in academic medicine N Engl I Med 2010;362:669-71.

24 Association of American Medical Colleges. Protecting patients, preserving integrity, advancing health: accelerating the implementation of COI policies in human subjects research. AAMC, 2008.

25 Association of American Medical Colleges. Industry funding of medical education: report of an AAMC task force. AAMC, 2008.

26 American Medical Association. Conflict of interest guidelines for organized medical staffs. AMA, 2007.

Web extra supplementary table: healthcare companies on NASDAQ and New York Stock

Exchange

included in sample 